Sociohistórica, no 41, e044, 1er. Semestre de 2018. ISSN 1852-1606

Universidad Nacional de La Plata.

Facultad de Humanidades y Ciencias de la Educación.

Centro de Investigaciones Socio Históricas

\title{
Los actos conmemorativos de "reparación" de legajos laborales de empleados estatales desaparecidos y las transformaciones en la narrativa en torno al pasado reciente argentino.
}

\section{Déborah Cinthia Balé *}

* Universidad Nacional de General San Martín - CONICET, Argentina cinthia.bale@yahoo.com

Cita recomendada: Balé , D. C. (2018). Los actos conmemorativos de "reparación" de legajos laborales de empleados estatales desaparecidos y las transformaciones en la narrativa en torno al pasado reciente argentino. Sociohistorica, 41, e044. https://doi.org/10.24215/18521606e044 
Los actos conmemorativos de "reparación" de legajos laborales de empleados estatales desaparecidos y las transformaciones en la narrativa en torno al pasado reciente argentino.

The commemoration practices dedicated to the 'disappeared' public workers and the transformations in social narratives on Argentina's recent past

Déborah Cinthia Balé

Universidad Nacional de General San Martin/

CONICET, Argentina

cinthia.bale@yahoo.com

\section{Resumen:}

En este artículo nos interesa describir y analizar el conjunto de actos conmemorativos realizados y/o promovidos por la Comisión de Trabajo por la Reconstrucción de Nuestra Identidad en el marco de la política de reparación de legajos laborales de los empleados estatales desaparecidos prevista por el Decreto $\mathrm{n}^{\circ} 1199$ del año 2012. Especialmente nos interesa dar cuenta de la emergencia del "trabajador estatal desaparecido" como figura novedosa a ser recordada y homenajeada en el régimen de memoria instalado en el país en torno al terrorismo de Estado, así como dar cuenta de una serie de transformaciones que se dieron en los modos de narrar el pasado reciente al interior de la Administración Pública Nacional durante el último gobierno kirchnerista (2011-2015).

Palabras Clave: Memoria, Identidad política, Trabajadores estatales.

\section{Aвstract:}

In this paper we intend to describe and analyze a number of public commemorations organized or promoted by the "Comisión de Trabajo por la Reconstrucción de Nuestra identidad" in the context of the reparation of personnel files that belonged to disappeared public servants as it was appointed by the executive order $\mathrm{n}^{\circ} 1199$ of the year 2012. We aim to explain the appearance of the "trabajador estatal desaparecido" as an original figure of remembrance, as well as the changes that took place in the narratives concerning the recent past inside the public administration during Fernández de Kirchner's term of office (2011-2015).

KeYWORDS: Memory, Political identity, Public servants.

\section{INTRODUCCIÓN ${ }^{1}$}

Los actos de recuerdo o conmemoración sobre el terrorismo de Estado han adoptado diversas formas a lo largo del tiempo. Su variación ha acompañado los momentos de "auge" y de "latencia" de las disputas en torno del pasado reciente y también ha reflejado los cambios en la actitud del Estado en relación con la gestión del pasado (Valdez, 2004). Durante los gobiernos kirchneristas (2003-2015) ${ }^{2}$ el protagonismo en la organización de actos conmemorativos, así como en otros aspectos de las denominadas "políticas de memoria", fue asumido principalmente por el Estado en un proceso de articulación, cogestión (Guglielmucci, 2013) o incluso en franca oposición (Alonso, 2009, 2011) con el movimiento de derechos humanos. Este proceso estuvo signado por el despliegue de una profusa actividad basada en la constitución de museos o memoriales así como en la identificación de los ex Centros Clandestinos de Detención y su reconversión en sitios de memoria (Da Silva Catela, 2014; Lvovich y Bisquert, 2008). Sin embargo, a la hora de analizar estas transformaciones y dar cuenta de los efectos de la implicación del Estado en la gestión del pasado reciente los aportes académicos han sido más bien fragmentarios y heterogéneos. Si bien la mayoría de los autores coincide en señalar que la llegada a la presidencia de Néstor Kirchner constituyó un punto de clivaje (Carnovale, 2006; 
Lvovich y Bisquert, 2008; Da Silva Catela, 2011), son pocos los trabajos que abordan específicamente los procesos de institucionalización de las memorias, no sólo en el período mencionado sino de manera general en los diferentes gobiernos democráticos que se sucedieron luego del fin de la dictadura militar ${ }^{3}$.

Dentro de este panorama, en este artículo nos proponemos ofrecer un análisis de los actos conmemorativos realizados y/o promovidos por la Comisión de Trabajo por la Reconstrucción de Nuestra Identidad en el marco de la política de reparación de legajos laborales de empleados desaparecidos prevista por el Decreto $\mathrm{n}^{\circ} 1199^{4}$. Este decreto, firmado en el año 2012 durante la segunda presidencia de Cristina Fernández de Kirchner ordenó el relevamiento y la reparación documental de los legajos laborales de quienes al momento de su desaparición o asesinato revistaban como empleados de la Administración Pública Nacional (APN). La reparación documental refería a la corrección por parte de las actuales autoridades de la información falsa que la dictadura militar había hecho constar en los legajos laborales ( $\mathrm{y}$ los respectivos cierres administrativos) en relación con el destino de los trabajadores desaparecidos y asesinados. Así el decreto mencionado ordenaba incluir en cada uno de los legajos recuperados una resolución que indicara la verdadera causa del cese laboral, es decir "la desaparición forzada o asesinato [según correspondiera] como consecuencia del accionar del terrorismo de Estado" 5 . En cumplimento de esta normativa la Comisión de Trabajo por la Reconstrucción de Nuestra Identidad (encargada de centralizar su aplicación) identificó y recuperó las historias de cientos de trabajadores del Estado desaparecidos. La reparación de los legajos supuso, a su vez, la realización de múltiples actos conmemorativos que, como dijimos, se llevaron a cabo en distintas dependencias a lo largo de la APN. En ellos, se recordó a los ex empleados y empleadas y se hizo entrega de los legajos reparados a sus familiares. Desde fines de 2013 a fines de 2015 se llevaron a cabo más de veinticinco actos en los que participaron, en la mayoría de los casos, los máximos representantes de cada organismo (ministros, directores, secretarios, etc.), además de organismos de derechos humanos, sindicatos, empleados actuales de la APN y familiares ${ }^{6}$.

En este artículo nos interesa describir y analizar este conjunto de actos conmemorativos en la medida en que nos permitirán mostrar una serie de transformaciones que se dieron en los modos de narrar el pasado reciente en el interior de la Administración Pública Nacional durante el último gobierno kirchnerista. Especialmente nos interesa dar cuenta de la emergencia del "trabajador estatal desaparecido" como figura novedosa a ser recordada y homenajeada en el régimen de memoria instalado en el país en torno al terrorismo de Estado. Esta novedad puede advertirse si tenemos en cuenta que, desde la narrativa instalada a partir del Informe Final de la Comisión Nacional sobre la Desaparición de Personas (CONADEP), las personas que habían sido víctimas de desaparición forzada eran clasificadas de un modo difuso según categorías ocupacionales (que incluían a obreros y empleados), ocupaciones concretas (como docentes, periodistas o abogados), e incluso calificaciones ocupacionales (Crenzel, 2008) que en ningún caso incluían como categoría independiente a los trabajadores de la Administración Pública Nacional. La construcción ex post facto de la categoría es un dato que nos proponemos explicar, tanto a la luz de las transformaciones en el régimen de memoria como del análisis acerca de quiénes y a partir de qué narrativas se construyó esta práctica de memoria: ¿cómo se representó a los trabajadores estatales desaparecidos en los "actos homenaje"? 7 ¿Qué vínculos se establecieron entre estas representaciones y las identidades políticas de los homenajeados? ¿De qué modo se vinculan estas representaciones con los sentidos otorgados al Estado y a los trabajadores estatales en el presente?

Con ese propósito dividiremos la exposición en dos partes: por un lado realizaremos algunas indicaciones sobre las formas de organización de los "actos homenaje" tratando de dar cuenta de los diferentes actores que intervinieron en ellos, así como de las modalidades y los efectos generados por su participación. Por otro lado analizaremos la puesta en escena de los actos conmemorativos prestando especial atención a los tópicos discursivos que se reiteraron y especialmente a la narrativa construida en torno a la rememoración de los empleados estatales desaparecidos. Para ello hemos trabajado con entrevistas orales semiestructuradas y abiertas, realizadas con los miembros de la Comisión así como con diferentes funcionarios y colaboradores. 
Dada la ausencia de trabajos en torno a esta política, las entrevistas fueron indispensables para recoger información fáctica y para dar cuenta de los modos de autorepresentación de los entrevistados en relación con la propia tarea. Los actos conmemorativos, por otra parte, fueron registrados mediante técnica de observación participante con grabación sonora y fotografías. Entendida como "una verdadera usina de contextos, es decir, de marcos de interpretación del fluir cotidiano y de las intervenciones discursivas" (Guber, 2011, p. 78), la observación participante nos permitió apreciar los sentidos dominantes en cada una de las conmemoraciones, los diferentes grados de emotividad o "mística" que se recreaban en ellas, así como la relación de los diferentes auditorios con las agencias en las que se llevaban a cabo los actos y los funcionarios involucrados. Por último, hemos recurrido al análisis de la normativa pertinente y prensa gráfica cuando lo consideramos necesario.

\section{Formatos, ACTORES Y MODOS DE DISTRIBUCIÓN DE LA PALABRA ${ }^{8}$}

Como hemos adelantado los actos conmemorativos que analizaremos aquí se llevaron a cabo entre diciembre de 2013 y noviembre de 2015 en diferentes dependencias que componen la Administración Pública Nacional. Con sus variaciones estos actos tuvieron como objetivo homenajear a los trabajadores estatales que fueron víctimas de desaparición forzada o asesinato, así como entregar sus legajos laborales "reparados" a sus familiares.

Si bien los diferentes actos contaron con la participación de algunas entidades sindicales y el apoyo de algunos de los organismos de derechos humanos, una de las particularidades que asumió el proceso de reparación y entrega de los legajos laborales fue que la organización de los actos conmemorativos estuvo bajo la responsabilidad de las autoridades de cada una de las dependencias ${ }^{9}$. Según lo establecía el Decreto n ${ }^{\circ} 1199$, la autoridad superior del organismo en el cual se localizara el legajo laboral a reparar debía producir su "enmienda material" incorporando al mismo una resolución conjunta de la Secretaría de Gabinete y Coordinación Administrativa y la Secretaría de Derechos Humanos de la Nación. Según lo dispone el decreto, el legajo así "reparado" debía ser entregado a la familia de la víctima con participación de la Comisión de Trabajo por la Reconstrucción de Nuestra Identidad (en adelante, la "Comisión") y a su vez remitido en copia al Archivo Nacional de la Memoria.

La participación de diferentes actores y, a su vez, la centralidad de las autoridades en la realización de los actos conmemorativos supuso diversas consecuencias. En términos prácticos es posible señalar que la participación de los funcionarios de las diferentes dependencias condicionó el formato de los actos que se realizaron según una modalidad fuertemente protocolar. Las principales excepciones fueron los actos que se realizaron en la Escuela Secundaria 9 "Justo José de Urquiza" de San Nicolás, Provincia de Buenos Aires, en homenaje a la docente Irma Zucchi, y el acto realizado por el Sindicato de Trabajadores Judiciales (SITRAJU), ya que ambos se realizaron al menos en parte en la vía pública y fueron convocados por diferentes actores sociales además de la Comisión ${ }^{10}$. En el resto de los casos, los actos se realizaron en el interior de los organismos o ministerios con una convocatoria cerrada que se organizaba en torno a la agenda del funcionario correspondiente. Esto determinó que hubiera demoras, postergaciones e incluso superposiciones, es decir, que se realizaran dos actos conmemorativos en dos dependencias diferentes en el mismo horario. Por otra parte, el nivel de articulación que se alcanzara entre los diferentes actores involucrados -entre los que cabe incluir no sólo a los funcionarios sino también a los familiares de las víctimas, los sindicatos, las "comisiones de memoria" preexistentes en algunos organismos (por ejemplo la Comisión de Reparación Histórica de los trabajadores de INTA o la Comisión por la Memoria, la Verdad y la Justicia del Ministerio de Economía) y los empleados actuales de las dependencias- influyó decisivamente en los modos de distribución de la palabra (es decir, en la definición de quiénes serían los oradores), así como en la masividad y envergadura de las convocatorias. Ello condicionó a su vez la posibilidad de que se singularizara de manera más o menos concreta la identidad de los homenajeados, es decir, que se pudieran indicar aspectos de sus desempeños en los organismos, sus militancias políticas o gremiales, sus vidas familiares, etc., más allá de su clasificación 
genérica como trabajadores estatales. Esta posibilidad de singularización estuvo atada a su vez a la cantidad de trabajadores recordados en cada acto cuyo número también era variable. De un total de veinticinco actos, en quince de ellos los homenajes eran individuales o por pares, mientras que en el resto podían ser grupos que iban de cuatro a cuarenta y dos (esta última es la cantidad de trabajadores homenajeados en el acto realizado en la sede de la compañía Yacimientos Petrolíferos Fiscales).

Por otra parte, se debe tener en cuenta que el papel preponderante de la voluntad política de las autoridades de las agencias estatales generó que la realización de las conmemoraciones no siguiera un orden prefijado, sino que éstas fueran realizándose a medida que aparecían los actores interesados y se lograba captar la atención de las autoridades involucradas ${ }^{11}$. Por eso, si bien la política de reparación documental ordenada por el decreto entró en vigencia en el año 2012, la mayoría de los actos se realizó en los dos últimos años de gobierno de Cristina Fernández de Kirchner: en 2014 se realizaron nueve "actos homenaje" de los cuales tres contaron con la participación de ministros. Al año siguiente el total de actos realizados ascendió a quince, con nueve participaciones ministeriales y la presencia frecuente del Secretario de Derechos Humanos de la Nación ${ }^{12}$. Parte de este crecimiento se vincula con la visibilidad que la tarea de la Comisión fue alcanzando en el interior de la Administración Pública Nacional y también con un contexto signado por la cercanía de las elecciones presidenciales. En efecto, desde el comienzo de la campaña electoral, el 20 de septiembre de 2015, hasta el ballotage del 22 de noviembre se realizaron seis de los quince actos realizados en ese año.

En este sentido, es destacable que uno de los principales obstáculos que enfrentó la Comisión (que, como señalamos era la encargada de relevar y recuperar los legajos laborales) radicó en que los funcionarios apreciaran la relevancia de la reparación y sus beneficios simbólicos en un contexto dominado por cuestiones de coyuntura. Según el relato de T, encargada de la articulación institucional de la Comisión con otros organismos y dependencias, "[los funcionarios] entienden el tema el día del acto o el día que toman contacto con los familiares, hasta que ellos no toman contacto es que no lo pueden ver..." ${ }^{13}$. Más aún, tal como la oradora de la Comisión se encargaba de señalar a la hora de hablar en los actos conmemorativos, la importancia simbólica de rectificar la información contenida en el legajo debía ser continuamente resaltada.

En esa línea, es importante señalar que, si bien el decreto ordenaba la reparación para todas las entidades que conformaban la APN, la realización del acto conmemorativo no fue una política seguida de manera uniforme por todos los organismos. Hasta noviembre de 2015 tres de los doce Ministerios en funcionamiento no habían estado involucrados en ningún acto conmemorativo de reparación de legajos (estos son Ministerio del Interior, Ministerio de Relaciones Exteriores y el Ministerio de Seguridad) y en lo que se refiere a la administración descentralizada sólo habían concretado reparaciones diecisiete organismos de un total aproximado de ochenta ${ }^{14}$. Si bien no es posible afirmar que todas ellas tuvieran legajos laborales pendientes de reparación (de hecho, algunas no existían en tiempos de la dictadura militar), las cifras dan cuenta del modo en que la realización de las conmemoraciones no constituía un mero trámite administrativo/burocrático sino que portaba otras significaciones. El hecho de que no todos los organismos del Estado cumplieran con lo ordenado por el decreto y además no lo hicieron con el mismo nivel de adhesión a la causa, involucramiento personal y celeridad, nos permite afirmar que la participación de los funcionarios en los actos conmemorativos excedía su dimensión práctica e incluía otras significaciones vinculadas tanto con el pasado como con el lugar que el recuerdo de ese pasado ocupaba en el presente de la gestión.

Para pensar este punto resulta útil recurrir al análisis de las conmemoraciones en términos de su carácter performativo. Como señala Schindel (2009), las conmemoraciones pueden ser consideradas prácticas performativas en la medida en que en ellas el recuerdo no se materializa en una tercera instancia -como en la construcción de museos y memoriales-, sino que se realiza en sí mismo. Según esta perspectiva, en los actos conmemorativos "la memoria es menos un relato apoyado en soportes diversos que un compromiso del cuerpo y un modo alerta de la conciencia; no un contenido a ser transmitido sino un acontecimiento colectivo" (p. 84). En ese sentido, es importante considerar que la participación en los actos como acontecimientos colectivos conlleva por sí misma un conjunto de significaciones vinculadas a la identidad 
de quienes conmemoran, independientemente de que, como sucedía en los casos analizados, el objeto del mismo se centrara en una inscripción o un soporte material como el legajo laboral. Como lo analizaremos a continuación, estas significaciones se expresan tanto en las diferentes intervenciones orales como en el conjunto de acciones rituales que daban forma a la conmemoración. $\mathrm{Al}$ respecto, nuestra hipótesis es que para las distintas agencias y ministerios que concretaron el acto conmemorativo su realización constituía una práctica que permitía a los funcionarios legitimar su vínculo con la "cuestión de la memoria" o "los derechos humanos" y al mismo tiempo performativizar la propia inscripción en el proceso político kirchnerista que, como veremos en lo que sigue, estaba en el centro de la narrativa propuesta en las conmemoraciones.

\section{LA CONSTRUCCión DE UNA COMUNIDAD DE RECUERDO: EL PAPEL DE LOS FUNCIONARIOS EN LOS ACTOS CONMEMORATIVOS}

El análisis del ritual contenido en los actos conmemorativos resulta valioso a la hora de identificar cuáles eran los límites que se trazaban en torno a la identidad de quiénes conmemoran y la construcción de un "nosotros" con legitimidad para recordar (Jelin, 2002). Al hablar de ritos o "acciones rituales" (Geertz, 1992; V. Turner, 1988) nos referimos a conductas específicas (palabras, actos, gestos y secuencias estructuradas) que resultan capaces de generar conciencia de identidad en un determinado grupo o colectivo. Dicho de otro modo, la apelación a un conjunto de elementos o símbolos que se distinguen por su capacidad performativa permiten, en el contexto de la acción ritual, celebrar la pertenencia a un grupo determinado (Rementería Arruza, 2006).

En ese sentido, es posible señalar una serie de conductas que se repetían en los diferentes actos conmemorativos que tuvimos ocasión de registrar. Usualmente los actos comenzaban con la presentación de un locutor o locutora que conducía la ceremonia y la inscribía en el marco normativo del Decreto n 1199

15 . Luego seguía la entonación del himno nacional. En tercer lugar se hacían los saludos y nombramientos de las autoridades presentes según una modalidad protocolar. A continuación se escuchaban los discursos de los oradores que solían ser: una representante de la Comisión de Trabajo por la Reconstrucción de Nuestra Identidad, las autoridades del organismo correspondiente, un representante de la Secretaría de Derechos Humanos de la Nación, y en ocasiones algún familiar. Luego de los discursos se procedía al sellado de legajos laborales con la leyenda "Legajo reparado. Decreto 1199/2012" y la entrega a las familias presentes. Para finalizar se tomaban fotografías oficiales y a veces se incluía el descubrimiento de placas alusivas, que podía realizarse al comienzo o al final del acto. Además era frecuente la entrega de folletería por parte de la Comisión para difundir su tarea y, en algunos casos, la exposición de fotografías de las personas que iban a ser recordadas. Antes de que el acto finalizara era usual que algún integrante de la Comisión pronunciara una conocida consigna acuñada por el movimiento de derechos humanos: “ $i 30.000$ compañeros desaparecidos, presentes! Ahora y siempre", con la correspondiente respuesta de los asistentes.

De esta serie de pasos es posible destacar el solapamiento de dos series de ritualidades: mientras la presencia de un locutor, la entonación del himno nacional, el sellado de legajos y los saludos protocolares remiten a una escenografía de lo oficial (Bourdieu, 2014), otras pautas, como la exposición de fotografías, la palabra de familiares e incluso la consigna mencionada, son prácticas más frecuentes en las conmemoraciones organizadas por los organismos de derechos humanos sin participación estatal. Este solapamiento habla de la porosidad existente entre las agencias estatales y los mencionados organismos (Guglielmucci, 2013; Cueto Rúa, 2016), pero también de un sentido relativo a la identidad de quienes conmemoran: se trata de funcionarios y agentes de la Administración Pública Nacional pero también de "militantes" o "compañeros" de los homenajeados; en suma, de sujetos que se perciben como comprometidos con la "causa de los derechos humanos" de manera previa o independiente a su responsabilidad institucional. En ese sentido, la mera presencia de los "funcionarios/compañeros" en los actos conmemorativos supone una transformación del modo en que quienes recuerdan se perciben y son percibidos. A contrapelo de la dinámica confrontativa que signó por mucho tiempo la relación del movimiento de derechos humanos con distintos sectores del Estado 
nacional (así como de los Estados provinciales y municipales) no hay aquí una oposición entre militantes y agentes estatales: la práctica de memoria los incluye a ambos en una relación de legitimación recíproca.

$\mathrm{Al}$ mismo tiempo, cabe notar que este solapamiento no está ausente de tensiones. Elementos como la bandera y el himno nacional, la enumeración de los cargos que detentan las autoridades así como el sello que se imprime a los legajos laborales remiten como dijimos a una "escenografía de lo oficial" o a una "teatralización" que es propia del Estado como invención organizativa. Sin embargo, estas "verdades públicas" u oficiales que se suponen inscriptas en el orden social (Bourdieu, 2014) se ven tensionadas por otro conjunto de significaciones que aparecen en los "actos homenaje" y que antes que escenificar acuerdos suponen, como veremos, contenidos específicos de adhesión a una determinada identidad política. Así, la construcción de un "nosotros" que recuerda supone una suerte de superposición entre un conjunto de reivindicaciones y sentidos particulares (vinculados a la inscripción de una memoria afín al proyecto político kirchnerista) sostenidos desde un escenario que prima fascie adquiere su potencia nominativa enmarcado en la escenografía de lo oficial. Más aún, si es cierto que, como señala Bourdieu, la performatividad del ritual se sostiene sobre la autoridad de quien lo enuncia (Bourdieu, 1985) es posible señalar una suerte de refuerzo entre dos lógicas: por un lado, aquella legitimidad que proviene de la adscripción a la "causa de la memoria" desde una perspectiva "militante" y por otro, la autoridad inherente a la posición del funcionario como "delegado".

En ese contexto la presencia de los funcionarios generaba a su vez un doble efecto: por un lado sancionaba el aval institucional a la tarea de reconocimiento de los trabajadores desaparecidos e introducía la cuestión del terrorismo de Estado en diversas reparticiones en el interior de la APN por primera vez. Este efecto se potenciaba en los casos en que se preveía la interrupción de las actividades laborales y/o se invitaba a los empleados de los organismos a asistir al acto conmemorativo. Por otro lado, como adelantamos, la participación de los funcionarios performativizaba o ponía en acto la propia identidad política. Por eso a la hora de explicar su creciente participación señalaba uno de los integrantes de la Comisión:

[Esa participación] es de ahora, es de este año. Evidentemente la temática se hizo visible. Y al ver la temática y si se llega a un entorno que lo pueda transmitir al ministro, capaz que se suman o les gusta, o evidentemente estamos en un momento en el Estado donde los ministros están comprometidos con esa temática (Entrevista a H, 3 de julio de 2015).

La noción de "compromiso" funciona aquí como una clave cargada de significación en la medida en que no se trata de una noción abstracta sino que se encuentra ligada a la pertenencia de los funcionarios al espacio político kirchnerista (el "proyecto nacional y popular"), y sobre todo al desarrollo de las denominadas políticas de memoria, verdad y justicia ${ }^{16}$. En este punto es interesante señalar el modo en que un cierto ethos militante ${ }^{17}$ (Montero, 2012) ocupa el imaginario de los agentes estatales respecto de sus tareas: aun cuando la reparación de los legajos laborales constituyera una obligación conforme el Decreto $n^{\circ} 1199$, la participación de los funcionarios en el proceso es interpretada como un signo de adhesión a un determinado proyecto político antes que como la expresión de una responsabilidad institucional. En ese sentido, la presencia de los funcionarios en las conmemoraciones pone en escena la pertenencia a un espacio político que se ve reforzada por el hecho de que, como lo señalamos arriba, no todos los organismos del Estado cumplimentaron con lo ordenado por el decreto, y ciertamente no todos los hicieron con el mismo nivel de adhesión a la política.

A su vez debe considerarse que la presencia de los ministros y otras autoridades adquiere un valor distintivo si se lo compara con el papel que tenían funcionarios de gobiernos anteriores en cuanto a su presencia en actos conmemorativos18. En efecto, el hecho de que los funcionarios de la gestión kirchnerista protagonizaran junto con familiares de desaparecidos un espacio de conmemoración y homenaje en el interior del Estado nacional no sólo constituyó una novedad de estos años, sino que además resultaba un modo simbólico de sancionar la cesura entre un "Estado terrorista" o un "Estado ausente" -tal era la representación compartida en estos actos sobre el rol del Estado en la década del noventa- y el "Estado kirchnerista": los funcionarios en el gobierno no eran ya calificados como "cómplices" o "responsables" de la impunidad de la dictadura (en parte gracias al desarrollo de los juicios por crímenes de lesa humanidad), ni eran identificados directamente 
con la faz represiva del Estado, sino que se integraban dentro de la narrativa de la memoria sostenida por los organismos de derechos humanos al tiempo que la tensionaban y la modificaban.

En este sentido, en los actos conmemorativos circulaba una representación del Estado según la cual el mismo se constituía por quienes fueron "compañeros" de las víctimas o bien por funcionarios más jóvenes que compartían con aquella "generación diezmada" la lucha por determinados valores y convicciones. Si seguimos este hilo, podríamos decir que lo que se recordaba en los "actos homenaje" no era sólo la ausencia de los trabajadores desaparecidos, sino la reactualización de un mandato heredado de la militancia setentista que se renovaba en el presente. Se trataba así de la puesta en escena de una vuelta o un retorno: quienes ocupaban los resortes del Estado se percibían como herederos de "los 30.000 compañeros desaparecidos", lo que los constituía como sujetos legítimos para recordar.

De manera simultánea puede señalarse que la participación de los funcionarios en los actos homenaje implicó además la puesta en escena de un reconocimiento de la responsabilidad del Estado en el ocultamiento de lo sucedido con los trabajadores y en última instancia en su desaparición forzada o asesinato. Este reconocimiento puede ser leído como una réplica a menor escala del pedido de perdón que formuló el entonces presidente Néstor Kirchner en la ex ESMA en ocasión del traspaso de dicho predio al Gobierno de la Ciudad de Buenos Aires, el 24 de marzo de 2004. Allí Kirchner no sólo se inscribió explícitamente "en esa «generación» de jóvenes militantes cuyas prácticas, valores, ideales, creencias y sentidos de la política reivindica" (Montero, 2012: 91) -de un modo similar a como lo haría luego el conjunto de funcionarios kirchneristas cuyos discursos pudimos registrar en los “actos homenaje" -, sino que además inauguraba una nueva gestualidad del Estado nacional respecto de los crímenes del pasado (Lvovich y Bisquert, 2008). En efecto, al menos cuatro funcionarios remedaron ese gesto en los actos conmemorativos pidiendo perdón a los familiares por haber mantenido la adulteración documental de los legajos durante todos estos años de democracia ${ }^{19}$.

Si tenemos en cuenta estos señalamientos la participación activa de los funcionarios condensa al menos dos elementos que resultan centrales para comprender el carácter novedoso del régimen de memoria en el que se inserta la "reparación" de los legajos laborales y la comunidad de recuerdo que la sustenta: la construcción de un "nosotros" con legitimidad para recordar, basada en la identificación del kirchnerismo como heredero de la militancia setentista y, al mismo tiempo, la instalación de una cesura respecto del Estado terrorista que, como lo ha señalado Montero para los usos de la memoria en los discursos del presidente Néstor Kirchner, se concibe en bloque junto con los gobiernos de la década del noventa. A continuación, analizaremos cómo estos elementos se reencuentran y resignifican en las intervenciones orales que pudimos relevar en los "actos homenaje".

\section{LA PUESTA EN ESCENA DE UNA NARRATIVA DE LA MEMORIA: LAS REPRESENTACIONES DOMINANTES EN LOS ACTOS CONMEMORATIVOS}

Si bien la figura del "trabajador estatal desaparecido" constituía el objeto del homenaje, es necesario advertir que en la mayoría de los actos su configuración asumió un carácter abstracto. Las referencias a las tareas y/ o trayectorias laborales de los homenajeados fueron escasas y sólo en algunos casos se mencionaron datos concretos sobre el rol que cumplían los trabajadores en cada uno de los organismos. Algo similar ocurrió con las menciones relativas a la participación gremial o sindical. Por otra parte, aunque la entrega de los legajos constituía el objetivo de la conmemoración, pocas veces se recurrió a ellos para reconstruir el universo laboral de los trabajadores. De hecho hasta la entrega efectiva del legajo muchos de los familiares desconocían el contenido del mismo. En uno de los casos en que se recurrió al legajo laboral la representación sobre las trabajadoras desaparecidas discurría de este modo: 
Graciela entró a trabajar al I.A.F el 1 de abril de 1970, como empleada administrativa. Trabajó en distintas áreas del Instituto, en créditos hipotecarios, en el área de retiros y pensiones y en auditoría. Mientras estaba trabajando en el instituto se recibió de abogada en el año 1975 y luego comenzó a estudiar sociología. Como les decía, el 28 de diciembre de 1976 fue secuestrada de la puerta del Instituto, ella permanece desaparecida y los testimonios dan cuenta de que enero de 1977 se la ve en el centro clandestino de detención que funcionó en la ESMA. El directorio del I.A.F en el año 77 declara cesante a Graciela por abandonar su trabajo, sin causa justificada. A pesar de que los padres habían iniciado reclamos aquí en el instituto diciendo que su hija faltaba de la casa y que desconocían el motivo. María Magdalena, empezó a trabajar en I.A.F el 21 de julio de 1974, también como empleada administrativa y el legajo da cuenta de que se desempeñó en el área de retiros y pensiones en el sector de intereses devengados. Ella presenta su renuncia el 23 de diciembre de 1976, renuncia que inmediatamente es aceptada por el directorio y ella también fue secuestrada el 28 de diciembre del 76. Graciela tenía 27 años al momento de su secuestro y María Magdalena 21 años, ella estaba estudiando psicología (Presidenta del I.A.F, Ivana Besmalinovich, acto en el I.A.F.P.R.P.M, 9 de noviembre de 2015).

Otro ejemplo puede leerse en la gacetilla interna que publicó el Instituto Nacional de Tecnología Industrial (INTI) con ocasión de la realización del “acto homenaje” en el cual se entregaron los legajos de Alfredo Giorgi y María del Carmen Artero, el 4 de agosto del 2015:

Alfredo tenía 33 años cuando fue detenido. Estaba casado y era doctor en química. Giorgi era investigador del Centro INTIPlásticos y estaba realizando algunos desarrollos de punta para la época tales como materiales plásticos para un combustible líquido para cohetería y otro de encapsulado de microsensores. A Giorgi se lo llevaron el 27 de noviembre de 1978 (Gacetilla interna del INTI, S/F).

María del Carmen Artero era secretaria del Centro INTI-Química y estaba de licencia cuando fue secuestrada el 11 de octubre de 1978 junto a su hija Carmen. La última vez que su hijo Pablo la vio fue en abril de 1978, seis meses antes de su desaparición. En septiembre de 1976 su casa, donde vivía con su familia, fue atacada por la Policía Federal. Desde hacía un tiempo, María del Carmen sabía que corría peligro y buscaba refugio, ya que dos años antes había presenciado el asesinato del padre Mujica. Además, había participado del gremio y estaba al tanto de la persecución sindical que ocurría en aquellos años. A María del Carmen primero la llevaron al Centro Clandestino de Detención conocido como "El Banco" y luego a "El Olimpo" (Gacetilla interna del INTI, S/F)

En ambos ejemplos la presentación de los "trabajadores desaparecidos" se realizaba a partir de un conjunto de datos básicos que remite a una clasificación de tipo demográfica (según el género, la edad, el estado civil) y socioocupacional (empleo, estudios alcanzados). A su vez, en ambos casos se mencionan datos vinculados a la materialidad del crimen: se presentan la fecha y el lugar del secuestro así como el lugar o centro clandestino de detención donde los trabajadores fueron vistos por última vez ${ }^{20}$.

Esta presentación sociodemográfica o socioocupacional, vinculada además a la materialidad del crimen, es una modalidad de identificación que puede rastrearse tempranamente tanto en los modos de representación desplegados por los familiares y por los organismos de derechos humanos en sus estrategias de resistencia a la dictadura, como en el informe final de la CONADEP publicado en 1984. Como señala Crenzel (2010), en ese momento la incorporación de la narrativa humanitaria en la producción de denuncias generó, junto con otros factores, que se privilegiaran en la representación de los desaparecidos aquellos datos que referían a su carácter de individuos cuyos derechos humanos habían sido avasallados antes que a su pertenencia política. En este marco fueron construidas expost facto categorías que agrupaban a los desaparecidos según criterios no políticos como "los desaparecidos judíos", "los desaparecidos españoles", las "desaparecidas embarazadas", los "periodistas desaparecidos" (Crenzel, 2010, p. 73). Si bien eran comprensibles en el contexto de la transición, estos agrupamientos producían un efecto paradójico: al mismo tiempo que posibilitaban la difusión de las denuncias a nivel internacional, ocultaban simultáneamente las "razones políticas" por las cuales los desaparecidos fueron víctimas, y la "matriz política selectiva” (p. 73) que los había avasallado.

Si tenemos en cuenta esto, la figura del "trabajador estatal desaparecido" que analizamos aquí como categoría a ser recordada se inscribe también en un esquema narrativo que implica cierto soslayamiento de las claves políticas como modos de identificación y que privilegia una presentación corporativa. 
Independientemente de las intenciones de los miembros de la Comisión (para quienes la reivindicación de la condición de "trabajadores" constituía una apuesta en sí misma) las dificultades a la hora de traer a la memoria la trama gremial y sindical, así como la conflictividad social e histórica en la que estaban insertos los trabajadores estatales, hacen que la potencialidad evocativa de la categoría encuentre allí su límite. De un modo similar, la mención a las características sociodemográficas, así como las referencias al secuestro y cautiverio (que, huelga aclararlo, no son exclusivas de los actos aquí analizados), hablan del modo en que la condición del cuerpo vejado continúa siendo el centro de la práctica de memoria. Incluso en estos actos cuya figura central es la del trabajador estatal, la pérdida del trabajo no aparece como un daño digno de ser rememorado y atestiguado: lo que se recuerda o se conmemora no son las bajas, cesantías o renuncias forzadas sino que, a la inversa, éstas adquieren sentido en la medida en que constituyeron un preludio a la desaparición ${ }^{21}$. Así se las menciona tanto en el Decreto n 1199 como en su reglamentación, cuando se indica que "la baja, cese, suspensión, limitación de los servicios, el despido o la renuncia forzada de estos trabajadores, fue un mecanismo utilizado como forma de persecución política previa a la desaparición forzada o asesinato" 22 . Dicho de otro modo, en continuidad con el relato memorial instalado desde la transición, el foco está puesto en la desaparición de un modo que omite otras formas de violencia perpetradas por el Estado, ya no en su faz clandestina sino legal. Así la persecución en el ámbito laboral y/o la pérdida del trabajo permanecen por fuera de la narrativa instituida: no adquieren un peso por sí mismas sino cuando son puestas en relación con los crímenes del poder desaparecedor.

Por otra parte, así como la referencia a la condición de trabajadores estatales tuvo un carácter más bien nominal es posible señalar que las representaciones relativas a la militancia en los "actos homenaje" se caracterizaron, hasta cierto punto, por la dilución de referencias históricas concretas. Desde una perspectiva crítica compartida por diferentes autores es posible señalar la recurrencia a la categoría de militancia setentista como sinónimo de un conjunto homogéneo y sin fisuras en el marco del cual se soslayan las diferencias que los distintos actores de la época sostenían entre sí. Así, por lo general estuvieron ausentes las alusiones a las agrupaciones u organizaciones a las que pertenecían los homenajeados y también algunos tópicos centrales del imaginario de la militancia setentista como socialismo, revolución o incluso liberación (Alonso, 2011) ${ }^{23}$.

La pregnancia de la clave humanitaria arriba señalada y el bloqueo discursivo que ella implica respecto de las identidades políticas de los desaparecidos obedece a un conjunto de razones que exceden por mucho la práctica de memoria aquí analizada. Al respecto, nos interesa señalar solamente que, como lo mencionaba Nicolás Casullo (2006), la imposibilidad de restituir en el presente el relato que dotaba de sentido a las prácticas de los actores homenajeados en las décadas del sesenta y setenta, esto es, el atravesamiento de experiencias revolucionarias, configura una especie de "borramiento de los mundos histórico simbólicos" (p. 38) de las personas desaparecidas, que es muy difícil de reponer o actualizar en el presente. Sumado a ello, parte de ese borramiento puede explicarse en función de lo que se ha denominado una "peronización" de los homenajes (Alonso, 2009, 2011), es decir una sobrerrepresentación del peronismo a la hora de referir las pertenencias políticas de los desaparecidos y también un predominio de las claves asociadas a dicha identidad para la interpretación del pasado reciente. Como señala Alonso esta peronización no se encuentra signada necesariamente por una impronta del peronismo setentista (muchos de sus tópicos continúan aún obturados), sino que debe ser entendida como un efecto de la hegemonía justicialista en la escena política. En la práctica esta hegemonía se refleja en la referida presencia en los actos conmemorativos de exmilitantes reconvertidos en agentes estatales que fueron compañeros de las víctimas, así como en la asociación (inscripta por los propios actores) entre las políticas llevadas adelante por el gobierno kirchnerista y los ideales emancipatorios de la década del setenta.

Dentro de este panorama, ya de por sí complejo, es posible interpretar algunas de las intervenciones presentes en los "actos homenaje" según otra mirada que se propone hacer hincapié en las novedades surgidas en los marcos de interpretación del pasado desde los años dos mil en adelante. Según este análisis, el discurso dominante en los actos conmemorativos puede inscribirse en una línea signada por la aparición en el escenario 
público de una nueva narrativa "producida por una tendencia del peronismo con ojos de izquierda" (Lesgart, 2006, p.182) que apuntó a reescribir la historia de los setenta desde una mirada menos anclada a la visión negativa que la "cultura política democrática" de los ochenta consignó respecto de aquella década. Esta narrativa, que tuvo a Néstor Kirchner como uno de sus principales enunciadores, se montó sobre la necesidad de restituir politicidad a la década del setenta y en ese mismo gesto inscribir al peronismo en un tiempo anterior a la derrota (p.184), es decir, por la necesidad de encontrar un nuevo lugar para el peronismo otrora "satanizado e impronunciable" (Casullo, 2005 en Lesgart, 2006, p. 183). En línea con las "memorias militantes", construidas desde mediados de la década del noventa, esta narrativa abandonó la centralidad que adquirió durante los años ochenta la representación de los desaparecidos como víctimas inocentes para acentuar su carácter de "luchadores populares", de acuerdo con determinados valores y convicciones. Veamos algunos ejemplos de esta narrativa:

Por eso este acto de reparación no es sólo para ellas sino que aquí está presente una generación de la cual ellas formaron parte, con profundos dolores, con profundas convicciones que fueron un ejemplo de luch a (...) Nuestro mejor homenaje a Graciela y Magda como la conocían sus amigos es recuperar la verdad histórica, fortalecer la memoria colectiva y reivindicar el trabajo de fuerte compromiso social y los valores que ellas tenian. (Presidenta del Instituto, Ivana Besmalinovich, acto en el I.A.F.P.R.P.M, 9 de noviembre de 2015).

\section{O bien:}

Este acto de reparación y de justicia nos pone una vez más en el centro de lo que hacemos y somos. Los compañeros que hoy recordamos dieron su vida por la justicia social, por hacer una Patria más igualitaria. Tenemos un doble logro: reparar los legajos y haber hecho realidad aquello por lo que tantos argentinos lucharon: las políticas de inclusión implementadas en los últimos 12 años. (Secretario general de la ANSES, Rodrigo Ruete, acto en ANSES, 5 de octubre de 2015)

Si seguimos el análisis propuesto por Montero (2012) para los usos de la memoria en los discursos de Néstor Kirchner, es posible señalar que aquí la militancia aparece ligada a la reivindicación de un conjunto de prácticas y valores según "un registro que acentúa más el carácter fraternal, afectivo, heroico y voluntarista de esa tradición que su aspecto más trágico” (Montero, 2012, p. 115). En ese contexto se reivindica a la generación de los setenta como ligada a una "praxis ético-moral, animada por la esperanza de cambio" (Lesgart, 2006, p. 183). Al hacer hincapié en las convicciones esta narrativa resignifica el carácter políticamente comprometido de aquella generación y relativiza la narrativa humanitaria que referimos arriba. En ese sentido, aun si el recuerdo de los homenajeados tal como se desarrollaba en los actos conmemorativos prescindía de las especificidades relativas a sus historias de militancia, es posible sostener que su carácter político se cifraba en la renovada inscripción de sus memorias en unas nuevas y determinadas coordenadas dentro del espacio político argentino. Al respecto, es llamativa la reiteración de dos tópicos discursivos que consideramos relativamente novedosos. El primero se aprecia en los siguientes ejemplos:

Quiero agradecer el esfuerzo que ha hecho este ministerio [de Economía] que lleva políticas, sin duda políticas de inclusión y distribución de la riqueza más importantes en los últimos años de la Argentina pero las lleva de la mano de los derechos humanos y eso siempre se lo digo a Axel [Kicillof]: "gracias, gracias por poder unir esas dos cosas tan importantes, que era la lucha de nuestros padres" (Secretario de Derechos Humanos de la Nación, Martín Fresneda, acto en el Ministerio de Economía, 1 de octubre de 2015)

La reparación no es solamente esto, estos legajos, sino la reparación de que hoy haya una Asignación Universal por Hijo, una asignación para nuestros compañeros desaparecidos, que haya un plan de viviendas como el PROCREAR, reparación para ellos, esa es la reparación, este es el camino que tiene que seguir este pueblo, estamos convencidos de que así el pueblo va a ser más feliz y seguramente ellos hubieran estado aquí también, aplaudiendo esto. (Subsecretario de Promoción de Derechos Humanos de la Nación, Carlos Pisoni, acto del Sindicato de Trabajadores Judiciales, 9 de noviembre de 2015)

Nos referimos a la identificación de las luchas de la militancia setentista con el proyecto político kirchnerista y, con ello, la decodificación de dichas luchas en clave de "derechos humanos". Se trata en ambos casos de dos funcionarios que son hijos de desaparecidos y que vinculan explícitamente las políticas del 
gobierno kirchnerista con la lucha de sus padres. En una clave anacrónica a la militancia de los sesenta y setenta, las políticas económico sociales llevadas adelante por el gobierno kirchnerista son decodificadas como políticas de derechos humanos. Esta identificación puede deberse a la extendida circulación que esta última noción alcanzó a la hora de pensar los conflictos sociales en el país desde la transición democrática (Jelin, 2005), pero también al referido abandono de las categorías de la militancia revolucionaria.

El segundo tópico se vincula con el trazado de una continuidad, ya mencionada, entre dictadura y neoliberalismo:

Este acto de reparación tiene que ver con un proceso mucho más profundo que vive nuestra patria en los últimos años
que es la recuperación de la memoria y, por lo tanto, la recuperación de la identidad y, por lo tanto, la pérdida del miedo.
Porque si algo ha significado este proceso histórico que estamos viviendo desde el 25 de mayo de 2003 es dejar atrás el
miedo. Miedo que se había instalado, que muchos no lo percibíamos pero que estaba ahí en el fondo nuestro, chiquito, a
veces impidiendo, a veces trabando que pudiéramos desplegar todo nuestro potencial. Y no fue un proceso de pocos años,
fue el terrorismo de Estado, fue una década donde también tuvimos miedo a la pérdida del trabajo, fundamentalmente
como elemento de disciplinamiento social y eso había que darlo vuelta, eso formaba parte de lo que Néstor Kirchner decía
"recuperar la autoestima". (Ministro de Trabajo, Carlos Tomada, acto en el I.A.F.P.R.P.M, 9 de noviembre de 2015)

Si bien el origen de esta clave, que vincula ambos procesos, puede rastrearse en la emergencia de las denominadas memorias "militantes" a mediados de la década del noventa (Lvovich y Bisquert, 2008) ${ }^{24}$, el discurso kirchnerista retoma esta continuidad entre dictadura y neoliberalismo y la resignifica, incorporando ambos procesos en un bloque temporal que va desde 1976 hasta 2001. Dicho bloque conforma un "pasado denostado" (Montero, 2012, p. 85) respecto del cual el proyecto kirchnerista se presenta a la vez como ruptura y como inauguración de un nuevo ciclo.

En esa línea esta última intervención resulta ilustrativa no sólo porque recupera de manera explícita la cuestión identitaria, sino porque reúne en un mismo vocablo - miedo-aquello que por razones diferentes podía considerarse común para la sociedad argentina, tanto en época de dictadura como de gobierno constitucional. Así, la noción de "miedo" funciona como un hilo conductor de aquél "pasado denostado" que el kirchnerismo habría venido a clausurar. En este discurso, el sentido de la práctica recordatoria va más allá del homenaje a los trabajadores desaparecidos y se transforma en un testimonio de aquello que se concibe como la superación de un tiempo histórico:

Si bien cuando uno reflexiona un poquito sobre el tema, rápidamente se da cuenta que el proyecto de la dictadura militar no era el proyecto de exterminio por el exterminio mismo, no era un proyecto guiado por la crueldad, por el horror, por el odio, sino que era una herramienta más de las tantas, tal vez la más inhumana, pero no por eso una más [sic] de las tantas herramientas que usó el liberalismo en argentina para instaurar un proyecto económico que no podía ser instalado si no era mediante el quiebre de lo que se venía haciendo en el país, particularmente desde el primer gobierno de Perón. Que era un proyecto de inclusión, de crecimiento, de industrialización, de soberanía, que se tuvo que destruir un proyecto político económico y social que en el país seguía vigente con sus variadas formas, pero se tuvo que coartar y desviar la trayectoria de la sociedad argentina a través de la más cruenta y más horrible de las dictaduras, a través de un verdadero genocidio (Ministro de Economía, Axel Kicillof, acto en el Ministerio de Economía, 1 de octubre de 2015)

Por último, a la "continuidad entre dictadura y neoliberalismo" se le agregan dos elementos. Por un lado, un peso renovado a la interpretación de carácter instrumental o economicista del proyecto represivo de la dictadura, según la cual la desaparición forzada de personas constituía una "herramienta" para instaurar un nuevo régimen social, por otro, la caracterización del primer gobierno peronista como "un proyecto de inclusión, de crecimiento, de industrialización, de soberanía”, cuya trayectoria también habría sido "desviada" por la dictadura militar y reanudada por el kirchnerismo. En este marco, la identificación entre dictadura y neoliberalismo resulta reactualizada y reinterpretada en función de la configuración de la identidad política kirchnerista que, como heredera tanto del primer peronismo como de la militancia setentista, se presenta como su antítesis. En efecto, según algunos autores, el kirchnerismo se caracteriza por inaugurar una doble ruptura: una de corto plazo respecto del menemismo y las consecuencias sociales de las reformas pro mercado, 
y una ruptura de largo plazo con la dictadura militar iniciada en marzo de 1976, que desarrolló un patrón socioeconómico regresivo cuyos efectos sociales perdurarían hasta el presente (Aboy Carlés, 2005; Barros, 2012). El discurso kirchnerista establece así "una continuidad y una identidad política, económica, ideológica y simbólica entre la última dictadura militar y un régimen económico -el neoliberalismo- cuyo corolario y máxima expresión se habrían manifestado en la década del noventa y en el estallido del año 2001" (Montero, 2012, p. 81). En este contexto, y a los fines de definir los marcos de memoria que resultaban dominantes en los actos conmemorativos, resulta evidente que las luchas de los sesenta y setenta, así como las identidades de los homenajeados, resultan reinterpretadas y reactualizadas en función de las necesidades de la propia comunidad de recuerdo.

\section{Conclusiones}

Los diferentes aspectos analizados aquí en torno a los actos conmemorativos en homenaje a los trabajadores estatales desaparecidos nos permitieron reconstruir algunas de las representaciones que circularon sobre el pasado reciente en el marco de un conjunto de agencias y ministerios de la Administración Pública Nacional. Como lo hemos señalado, el análisis de estos actos es especialmente significativo en la medida en que, al incluir a un importante conjunto de funcionarios kirchneristas, nos permite trazar un panorama de las representaciones sostenidas por esta fuerza política en los marcos de interpretación del pasado. En ese sentido, hemos destacado de qué modo la construcción de un "nosotros" que recuerda supuso el solapamiento de dos tipos de ritualidades, una derivada de la escenografía estatal como invención organizativa y otra vinculada a un conjunto de reivindicaciones y sentidos asociados al "proyecto político kirchnerista". Respecto de éste y en relación con los modos de rememoración del pasado, nos encontramos con una renovada reivindicación de la militancia peronista de los años setenta y el trazado de una frontera respecto de un "pasado denostado" (Montero, 2012), concebido como una continuidad entre dictadura y neoliberalismo. También hemos mostrado en qué sentido se establece una equivalencia entre las luchas del pasado y las disputas del presente kirchnerista en clave de derechos humanos. Por otra parte, hemos señalado de qué modo (a pesar de las novedades) algunos de los elementos vigentes en los regímenes de memoria previos continúan signando las fronteras de decibilidad en torno al pasado reciente. Así, aun cuando la reivindicación de la militancia de la década del setenta habilitó una cierta repolitización de las víctimas del terrorismo de Estado (especialmente si se lo compara con la "memoria oficial" sostenida desde el Estado durante la transición democrática), el horizonte revolucionario propio de aquella década continúa por diversas razones obturado. En esa misma línea, hemos señalado de qué modo la noción del “cuerpo vejado" continúa siendo el centro de la práctica de memoria, aun en el marco de una narrativa que se propuso reparar las violencias perpetradas por el Estado en el ámbito laboral. Lo que se reconoce primariamente como crimen (y por ende quienes son reconocidos como víctimas) es la desaparición o el asesinato de un modo que ignora las violencias ejercidas por las diferentes agencias estatales en utilización de sus funciones legales o burocráticas durante la dictadura.

Una última cuestión a pensar se vincula con el posicionamiento de la figura del trabajador como víctima del terrorismo de Estado. Si bien el tema no ha sido explorado todavía por los estudios de memoria, es posible sugerir que dicha centralidad se ubica en un proceso más general según el cual los trabajadores fueron de algún modo reposicionados como víctimas del terrorismo de Estado, tanto desde instancias académicas como políticas y judiciales ${ }^{25}$. Este desplazamiento, cuyo auge puede vincularse con las investigaciones relativas a la complicidad empresarial con la dictadura, resulta particularmente novedoso en el caso analizado, ya que se refiere no a los trabajadores a secas sino a los trabajadores cuyo empleador era el Estado nacional. En este sentido, la representación de los desaparecidos no sólo como víctimas, sino como parte del Estado en tanto empleados de la administración pública constituye una novedad respecto del régimen de memoria imperante en los años noventa. En aquellos años esta asociación era difícilmente sostenible porque el Estado seguía siendo el principal objeto de impugnación del movimiento de derechos humanos en relación con el pasado 
dictatorial -respecto del cual funcionaba como garante de la impunidad-, y también, de modo creciente, respecto de las políticas que se desarrollaban bajo el signo del neoliberalismo.

Si tenemos en cuenta esto, durante el período aquí analizado se produjo una nueva representación de los desaparecidos en el marco de la cual las ansias de transformación social que les eran atribuidas ya desde la década del noventa, se proyectan no desde su militancia política -como era habitual-, sino desde el trabajo que desempeñaban en el Estado, concebido ahora como una forma de compromiso social. Bajo esta nueva impronta, los trabajadores estatales desaparecidos pasan a ser "ejemplos" a seguir por sus "compañeros" actuales de la administración pública, quienes los recuerdan y los reivindican en una línea de conexión tan imaginaria como efectiva.

Así, puede decirse que los actos conmemorativos se sostuvieron sobre la base de una transferencia simbólica según la cual la noción cristalizada del compromiso con ciertos valores, que se atribuían a la militancia de los desaparecidos, resulta proyectada sobre su trabajo en el Estado. Dicho de otro modo, la categoría de trabajador estatal aparece concebida no como una circunstancia más o menos azarosa dentro de una trayectoria laboral, sino como el producto de una posición subjetiva que daría cuenta de determinadas convicciones

Así, según la narrativa que hemos analizado a lo largo del artículo, es posible derivar del trabajo en el Estado un compromiso político que se identifica con el proyecto kirchnerista, y que, en ese mismo gesto, desplaza las referencias al imaginario revolucionario o socialista propio de la militancia setentista. Por eso el sentido de la memoria no debe buscarse en el pasado sino en el presente: la reivindicación de los "compañeros" desaparecidos qua trabajadores estatales (con independencia de su identidad política) es una construcción hecha a posteriori que adquiere su sentido en el marco de la construcción de una identidad política kirchnerista y sus modalidades de ocupación del Estado.

Dicho de otro modo, las representaciones que resultaron dominantes en la práctica de memoria analizadas son un índice del modo en que los "actos homenaje" constituyeron espacios de consolidación de una determinada comunidad de recuerdo. Los actos conmemorativos resultaron, así, prácticas de memoria performativas donde lo que se realiza no es tanto la memoria “en sí misma”, sino la redefinición o puesta en escena de la identidad de quienes participaban en ellos. En el marco de estas conmemoraciones, los actores dotaron de un sentido histórico su inscripción política en el presente anclándola a una selección del pasado (esto es, a una memoria) y a una promesa de futuro. En ese sentido hay un uso "político" del pasado, siempre que se entienda por ello el proceso de reapropiación y reinterpretación de un legado en el presente.

\section{REFERENCIAS}

Aboy Carlés, G. (2005). Populismo y democracia en la Argentina contemporánea. Entre el hegemonismo y la refundación. Estudios Sociales. Revista Universitaria Semestral, XV,125-149.

Alonso, L. (2006). Actos de memoria. Los homenajes de detenidos-desaparecidos y asesinados por el terror de Estado en Santa Fe 1998-2006, en 3ras. Jornadas de Estudios de Población y Sociedad de Córdoba, Santa Fe y Entre Ríos, Santa Fe, 9 y 10 de noviembre de 2006.

Alonso, L. (2009). Memorias sociales y Estado en Santa Fe, Argentina, 2003-2008. Política y cultura, 31, 27-47.

Alonso, L. (2011). Vaivenes y tensiones en la institucionalización de las memorias sobre el terror de Estado. El caso de Santa Fe, Argentina, entre 1983 y la actualidad. Cuadernos de Historia, Serie Ec. y Soc., 12, 35-70.

Andriotti Romanin, E. (2012). De la resistencia a la integración. Las transformaciones de la Asociación Madres de Plaza de Mayo en la "era Kirchner”. Estudios Políticos. Universidad de Antioquia, Colombia, 41, 35-54.

Barros, M. (2012). Democracia y derechos humanos: dos formas de articulación política Argentina, en E-l@atina. Revista electrónica de estudios latinoamericanos,29, 3-18.

Bourdieu, P. (1985). Los ritos de institución. En ¿Qué significa hablar? (pp. 78-86). Madrid: Akal.

Bourdieu, P. (2014). Sobre el Estado. Cursos en el Collège de France (1989-1992). Barcelona: Anagrama. 
Carnovale, V. (2006). Memorias, espacio público y Estado: la construcción del museo de la memoria. Estudios AHILA de Historia Latinoamericana, 2. Disponible en: http://riehr.com.ar/archivos/Investigacion/Carnovale\%20-\%2 0Museo\%20de\%20la\%20ESMA.pdf

Casullo, N. (2006). Memoria y revolución. Lucha Armada en la Argentina, 6, 32-42.

Catela Da Silva, L. (2014). "Lo que merece ser recordado..." Conflictos y tensiones en torno a los proyectos públicos sobre los usos del pasado en los sitios de memoria. Clepsidra. Revista Interdisciplinaria de Estudios sobre Memoria, 2, 28-47.

Crenzel, E. (2008). La historia politica del Nunca Más. Buenos Aires: Siglo XXI.

Crenzel, E. (2010). La víctima inocente: de la lucha antidictatorial al relato del Nunca Más. En E.Crenzel (ed.), Los desaparecidos en Argentina. Memorias, representaciones e ideas (1983 -2008), 65-84. Buenos Aires: Biblos.

Cueto Rúa, S. (2016). Ampliar el círculo de los que recuerdan' La inscripción de la Comisión Provincial por la memoria en el campo de los derechos humanos y la memoria (1999-2009) (Tesis doctoral), Universidad Nacional de La Plata. Disponible en: http://www.memoria.fahce.unlp.edu.ar/library?a=d\&c=tesis\&d=Jte1313.

Geertz, C. (1992). La interpretación de las culturas. Barcelona: Gedisa

Guber, R. (2011). La observación participante como sistema de contextualización de los métodos etnográficos: La investigación de campo de Esther Hermitte en los Altos de Chiapas, 1960-1961. Revista Latinoamericana de Metodologia de las Ciencias Sociales, 1 (2), 60-90. Disponible en: http://www.memoria.fahce.unlp.edu.ar/art_r evistas/pr.5188/pr.5188.pdf

Guglielmucci, A. (2013). La consagración de la memoria. Una etnografía acerca de la institucionalización del recuerdo sobre los crimenes del terrorismo de Estado en la Argentina. Buenos Aires: Antropofagia.

Jelin, E. (2002). Los trabajos de la memoria. Madrid: Siglo XXI.

Jelin, E. (2005). Los derechos humanos entre el Estado y la sociedad. En J. Suriano (Dir.), Nueva Historia Argentina, T.X, Dictadura y Democracia (1976-1999), 507-555.Buenos Aires: Sudamericana.

Lesgart, C. (2006). Luchas por los sentidos del pasado y el presente. Notas sobre la reconsideración actual de los años '70 y' '80. En C. Tcach y H. Quiroga (comps.), Argentina 1976-2006. Entre la sombra de la dictadura y el futuro de la democracia, 167-198. Rosario: Homo Sapiens.

Lvovich, D., y Bisquert, J. (2008). La cambiante memoria de la dictadura militar desde 1984: Discursos públicos, movimientos sociales y legitimidad democrática. Buenos Aires: UNGS/Biblioteca nacional.

Messina, L. (2014). Lugares y políticas de la memoria: a propósito de las tensiones en la calificación de las víctimas. Clepsidra. Revista Interdisciplinaria de Estudios sobre Memoria, 2, 66-79.

Montero, A. S. (2012). ;Y al final un día volvimos! Los usos de la memoria en el discurso kirchnerista (2003-2007). Buenos Aires: Prometeo.

Pollak, M. (2006). Memoria, olvido y silencio.La Plata: Al Margen Editora.

Rementería Arruza, D. (2006). Algunos conceptos teóricos para el análisis performativo de un rito secularizado. Zainak, 28, 105-123.

Schindel, E. (2009). Inscribir el pasado en el presente: memoria y espacio urbano. Política y cultura, 31, 65- 87.

Turner, V. (1988). El proceso ritual. Madrid: Taurus.

Valdez, P. (2003). El parque de la memoria en Buenos Aires. En E.Jelin y V. Langland (comps.), Monumentos, memoriales y marcas territoriales, 97-112. Madrid: Siglo XXI

Valdez, P. (2004). Iniciativas de memoria: formas de representación y conmemoraciones en Argentina. En R. Belay, J. Bracamonte, C. I. Degregori, et al, Memorias en conflicto. Aspectos de la violencia politica contemporánea, 285-297. Institut français d'études andines.

Vezzetti, H. (2009). Sobre la violencia revolucionaria. Memorias y olvidos. Buenos Aires: Siglo XXI. 


\section{Notas}

1 Este artículo se inscribe en el marco de la investigación doctoral que llevo adelante en la Facultad de Ciencias Sociales de la Universidad de Buenos Aires y retoma los resultados de mi tesis de maestría en Ciencia Política "La Comisión de Trabajo por la Reconstrucción de Nuestra Identidad y los procesos de encuadramiento estatal de las memorias sobre la represión" defendida en el Instituto de Altos Estudios Sociales de la Universidad Nacional San Martín.

2 Nos referimos a los gobiernos encabezados por Néstor Kirchner (2003-2007) y Cristina Fernández de Kirchner en dos períodos consecutivos (2007-2015). La asunción de un rol central por parte del Estado en la gestión del pasado reciente fue un vector común a todo el período, especialmente en lo referido a las memorias colectivas en torno al terrorismo de Estado.

3 Para el período que nos ocupa, puede verse el análisis de Luciano Alonso $(2009,2011)$ en torno a los procesos de institucionalización de memorias a partir del caso santafesino; Hugo Vezzetti (2009) para el análisis del vínculo entre las agencias estatales y los organismos de derechos humanos en los casos del Espacio para la Defensa y Promoción de los Derechos Humanos ex ESMA y del Parque de la Memoria en la Ciudad de Buenos Aires; Ana Guglielmucci (2013) para la incorporación de numerosos activistas de derechos humanos al Gobierno de la Ciudad de Buenos Aires entre fines de la década del noventa y principios de los años dos mil; Ludmila Da Silva Catela (2014) para una lectura del proceso de institucionalización en términos de las "memorias en conflicto" y Santiago Cueto Rúa (2016) para un análisis de la Comisión Provincial por la Memoria de la Provincia de Buenos Aires. Para el análisis específico de algunas iniciativas de gestión estatal de los sitios de memoria puede verse Estela Schindel, 2009; Guglielmucci, 2013; Luciana Messina, 2014 , 2015. En lo que se refiere a la creación del Parque de la Memoria y el Monumento a las Víctimas del Terrorismo de Estado véase Patricia Valdez, (2013) y Virginia Vecchioli, $(2001,2013)$ y respecto de la creación de un espacio - museo en la ex ESMA, véase también Carnovale (2006), Guglielmucci (2013), Da Silva Catela (2014), entre otros.

4 La Comisión de Trabajo por la Reconstrucción de Nuestra Identidad es una práctica de memoria que surgió en el año 2007 gracias a la labor de un conjunto de empleados de la Secretaría de Obras Públicas de la Nación, que se propuso "reconstruir" la memoria de los trabajadores estatales desaparecidos o asesinados por el terrorismo de Estado. Su existencia formal es el producto de la firma de un acuerdo de colaboración entre la mencionada secretaría y el Archivo Nacional de la Memoria. Este acuerdo tenía por objeto la identificación del personal del entonces Ministerio de Obras Públicas y Servicios que fue víctima de desaparición forzada durante la dictadura militar (1976-1983), así como la realización de otras actividades vinculadas con la reconstrucción del accionar del terrorismo de Estado en dicha repartición. Desde la salida del Decreto ${ }^{\circ} 1199$ del año 2012, que ordenó la reparación de los legajos laborales para toda la APN, la Comisión fue alcanzando cierta estabilidad institucional y pasó a estar conformada por un "núcleo duro" de cinco a siete personas que se desempeñaban como empleados del Ministerio de Planificación Federal. Asimismo, contaba con un conjunto de colaboradores entre los cuales se contaban hijos e hijas de personas desaparecidas o asesinadas y exempleados de la Administración Pública Nacional que habían sido dejados cesantes durante la dictadura militar. En la actualidad la Comisión de Trabajo por la Reconstrucción de Nuestra Identidad continúa su tarea de identificación y reparación de legajos laborales en el marco de la Secretaría de Obras Públicas del Ministerio del Interior, Obras Públicas y Vivienda, bajo el mandato del presidente Mauricio Macri.

5 Decreto ${ }^{\circ} 1199,19$ de julio 2012 (Boletín Oficial, 20 de julio 2012)

6 Los organismos, reparticiones y empresas donde se realizaron actos conmemorativos de entrega de legajos laborales fueron: Ministerio de Salud, Ministerio de Desarrollo social, Ministerio de Economía, Ministerio de Trabajo y Seguridad Social, Instituto Nacional de Tecnología Industrial, Instituto Nacional de Tecnología Agropecuaria, Instituto de Ayuda Financiera para el Pago de Retiros y Pensiones Militares, Comisión Nacional de Energía Atómica, Administración Federal de Ingresos Públicos, Administración General de Puertos, Administración Nacional de Seguridad Social, Ente Nacional de Obras Hídricas de Saneamiento, Servicio Nacional de Sanidad y Calidad Agroalimentaria, Casa de Moneda Argentina, Dirección Nacional de Vialidad, Centro Cultural de la Memoria Haroldo Conti, Hospital Nacional "Profesor Alejandro Posadas" y las empresas Aerolíneas Argentinas y Yacimientos Petrolíferos Fiscales.

7 Ponemos la expresión entre comillas ya que designa el modo en que los integrantes de la Comisión se referían a los actos conmemorativos.

8 El análisis que realizamos en este apartado se basa en el registro de siete actos conmemorativos de un total de veinticinco. Estos fueron los actos realizados en el Instituto Nacional de Tecnología Agropecuaria, Dirección Nacional de Vialidad, Ministerio de Salud y Ministerio de Desarrollo social, Ministerio de Economía, Instituto de Ayuda Financiera para el Pago de Retiros y Pensiones Militares, Sindicato de Trabajadores Judiciales y Hospital Nacional "Profesor Alejandro Posadas”. El registro de los actos se realizó mediante técnica de observación participante con grabación sonora en cuatro de ellos y fotografías. Para referirnos al resto de los actos contamos con reseñas de prensa, gacetillas oficiales y los relatos de diferentes participantes que fueron entrevistados. Incluimos también el acto homenaje a los trabajadores desaparecidos 
de Empresa Nacional de Correos y Telégrafos que se llevó a cabo en el Centro Cultural Kirchner el 14 de noviembre de 2015, aunque el objetivo del mismo no era la entrega de legajos sino la colocación de baldosas conmemorativas.

9 La variedad en las modalidades organizativas así como la autonomía de cada una de las dependencias a la hora de cumplimentar el Decreto $n^{\circ} 1199 / 12$ es indicativa del carácter heterogéneo y uniforme de aquello que llamamos Estado. Si bien dicha noción aparece como tal en los discursos y representaciones que aquí analizamos, el estudio que presentamos parte de considerar la especificidad de una agencia estatal como es la Secretaría de Obras Públicas de la Nación, y dentro de ella la Comisión de Trabajo Por la Reconstrucción de Nuestra Identidad, con el propósito de evitar generalizar o sustanciar la intervención del Estado en la temática.

10 El acto realizado en San Nicolás fue organizado y convocado conjuntamente con la Mesa de la Memoria por la Justicia de San Nicolás, el Sindicato Unificado de Trabajadores de la Educación de Buenos Aires (SUTEBA) y el Ministerio de Educación de la Nación el 15 de septiembre de 2015. En dicho acto, se entregó el legajo reparado de la docente a sus familiares y se colocó en la vereda del colegio una baldosa conmemorativa construida por alumnos de la institución. En el caso de SITRAJU, el acto se llevó a cabo frente al edificio del Consejo de la Magistratura en homenaje a diecinueve empleados judiciales asesinados o desaparecidos por la dictadura militar. En este caso, fue la comisión de derechos humanos del sindicato la que impulsó la reparación de los legajos ya que su corrección no estaba contemplada por el Decreto n 1199 (el mismo se restringía a los trabajadores de la Administración Pública).

11 Esto explica también que los primeros ciento veintidós legajos cuya reparación se preveía en el Decreto nº 1199 no necesariamente se encuentran entre los primeros que fueron entregados a las familias en los actos conmemorativos (Resolución $n^{\circ}$ 493, Secretaría de Gabinete y Coordinación Administrativa (SGCA), 4 de diciembre de 2012. BO, 6 de diciembre 2012). Por lo que pudimos relevar se han entregado públicamente alrededor de cincuenta. También han habido organismos donde se realizaron dos actos conmemorativos a raíz de la localización de nuevos casos. Esto ha ocurrido en Aerolíneas Argentinas, en la Administración Nacional de la Seguridad Social (ANSES) y en el Ministerio de Economía de la Nación.

12 Los ministros que participaron fueron: Axel Kiciloff (Economía) y Carlos Tomada (Trabajo) que participaron en dos ocasiones, Agustín Rossi (Defensa), Alicia Kirchner (Desarrollo social), Daniel Gollan (Salud), Alberto Sileoni (Educación) y Déborah Giorgi (Industria). Puede incluirse en esta lista a Teresa Parodi (Cultura) quien participó en un acto en conmemoración de los trabajadores desaparecidos de Empresa Nacional de Correos y Telégrafos (Encotel) que se llevó a cabo en el Centro Cultural Kirchner.

13 Entrevista de la autora a T, integrante de la Comisión de Trabajo por la Reconstrucción de Nuestra Identidad, 2 de septiembre de 2015. Las identidades de los miembros de la Comisión han sido reemplazadas por letras para asegurar la confidencialidad de las entrevistas.

14 Esta variedad en las formas de aplicación de la política de reparación de legajos laborales remite nuevamente al carácter no homogéneo de las agencias estatales y sus diversas lógicas de funcionamiento. Véase arriba nota 8.

15 Por lo general la fórmula seguida por los locutores era: "En el marco de la política de Estado "memoria, verdad y justicia”, iniciada el 25 de mayo de 2003, el gobierno nacional ha dispuesto mediante el Decreto presidencial ${ }^{\circ} 1199$ del 19 de julio de 2012 el relevamiento y reparación material de los legajos de los empleados de la Administración Pública Nacional desaparecidos o asesinados entre 1955 y 1983" (Locutor, Acto en el Ministerio de Salud, 4 de agosto de 2015)

16 Entrevista de la autora a T, integrante de la Comisión de Trabajo por la Reconstrucción de Nuestra Identidad, 2 de septiembre de 2015.

17 Según Montero el ethos militante que se proyecta en el discurso kirchnerista "se figura como la encarnación de un legado y un mandato heredados del pasado y que enraíza su práctica política en valores, ideas, convicciones, modos de hacer y de decir la política que lo preceden y lo constituyen” (Montero 2012, p. 296).

18 Por ejemplo, en julio de 1999, en ocasión de la colocación de la piedra fundamental del Monumento a las víctimas de Terrorismo de Estado en el Parque de la Memoria en la Ciudad de Buenos Aires, las madres de desaparecidos agrupadas en la Asociación Madres de Plaza de Mayo, algunos miembros de la Asociación de Ex Detenidos Desaparecidos y de H.I.J.O.S insultaron a los legisladores y miembros de partidos políticos por considerar que pertenecían a las mismas fuerzas políticas que votaron las leyes de Punto Final y Obediencia Debida. Véase Tappatá de Valdez, P. (2003), El parque de la memoria en Buenos Aires, en Jelin., E. y Langland, V., (comps.) Monumentos, memoriales y marcas territoriales, Madrid: Siglo XXI

19 Estos fueron: la presidenta del consejo de la magistratura Gabriela Vázquez, el presidente de Aerolíneas Argentinas Mariano Recalde, el CEO de YPF Miguel Galuccio y la presidente de Casa de Moneda, Katia Daura. La intervención de Galuccio puede verse en línea en el canal de YPF en youtube: https://www.youtube.com/watch?v=gau2oCQz-ug (Fecha de consulta 15/05/2016)

20 Esto resulta evidente también en la gacetilla interna producida por el Ministerio de Trabajo, en ocasión del acto conmemorativo que se realizó el 26 de marzo de 2015, en la cual sólo se mencionaba que "se entregó el legajo 'reparado' a los familiares de Guillermo Osvaldo Paryszewski, trabajador de la Delegación Córdoba del Ministerio, secuestrado y 
desaparecido". Ministerio de Trabajo, Empleo y Seguridad Social, Gacetilla de prensa "Tomada y Fresneda encabezaron acto de reparación histórica a trabajador desaparecido en la dictadura", Buenos Aires, 26 de marzo de 2015.

21 Agradezco a la Dra. Marina Franco haberme señalado este punto en el marco del núcleo "Política, sociedad y cultura en la historia reciente del Cono Sur", con sede en el IDAES/UNSAM.

22 Resolución no 493, Secretaría de Gabinete y Coordinación Administrativa (SGCA), 4 de diciembre de 2012 (BO, 6 de diciembre 2012).

23 Una excepción a esta observación la constituye el cuadernillo que se entregó a los participantes en el acto de homenaje a Marta Sierra y Carlos Alberto Costa, que se llevó a cabo en la sede Castelar del Instituto Nacional de Tecnología Agropecuaria (INTA) el 2 de junio de 2015. Allí se reúnen las biografías de seis trabajadores del INTA desaparecidos con referencias concretas a sus espacios y organizaciones de militancia. El cuadernillo fue elaborado por la Comisión de Reparación Histórica del INTA con la colaboración de los familiares de las víctimas.

24 Como señalan Lvovich y Bisquert (2008), la emergencia de dicha clave -según la cual la dictadura se representaba como condición de posibilidad de la implementación de un sistema político y económico neoliberal que para mediados de los noventa había sumido al país en una profunda crisis social- puede situarse en la "Declaración Popular" que las organizaciones convocantes leyeron en ocasión de la conmemoración del vigésimo aniversario del golpe de Estado. Según estos autores "a las conocidas consignas de repudio a las leyes del perdón y al reclamo de verdad y justicia se sumó una resignificación del golpe de Estado, visualizado desde entonces como el detonante no sólo del terrorismo ilegal sino también de políticas devastadoras que se extendían hasta aquel momento" (Lvovich y Bisquert, 2008, p. 65)

25 En la escena pública tuvieron especial resonancia las investigaciones relativas al caso Papel Prensa, así como la causa judicial en la que está imputado el empresario Carlos Blaquier, dueño del Ingenio Ledesma. Asimismo, es necesario mencionar la creación de la Comisión Bicameral de identificación de las complicidades económicas y financieras durante la última dictadura cívico militar en noviembre de 2015 y algunas publicaciones relativas a la temática, por ejemplo el texto de J. P. Bohoslavsky y H. Verbitsky (2014) Cuentas pendientes. Los cómplices económicos de la dictadura, Buenos Sires: Siglo XXI. 